\title{
Effect of Processing Conditions on Tensile Properties of Green Composites of Castor Oil Cake Starch-Plant Fibers
}

\author{
José Luis Guimarães ${ }^{1}$, Ana Cristina Trindade Cursino ${ }^{2}$, Cyro Ketzer Saul ${ }^{3}$, Maria Rita Sierrakowski², Luiz Pereira Ramos ${ }^{2}$, Fernando \\ Wypych ${ }^{2}$ and Kestur Gundappa Satyanarayana ${ }^{2 *}$ \\ ${ }^{1}$ Professional Education and TechnologySector; Federal University of Paraná - UFPR, Central Politechnic, Alcides Vieira Arcoverde Raod, 1225; Jardim das Américas, \\ 81520-260, Curitiba -PR - Brazil \\ ${ }^{2}$ Department of Chemistry, Federal University of Paraná, Central Politechnic,P.O. Box 19081, Jardim das Américas, $81531-980$ Curitiba, Paraná, Brazil \\ ${ }^{3}$ Departament of Physics, Federal University of Paraná, Central Politechnic,P.O. Box 19044, Jardim das Américas, 81531-980, Curitiba -PR - Brazil
}

\begin{abstract}
The authors have characterized castor oil cake (COS) and 'crude' glycerin (CG) and carried out preliminary studies to assess their composites containing plant fibers prepared under manual conditions. Based on the results obtained in the study, efforts were made to prepare similar 'green' composites under controlled conditions. This paper presents preparation and characterization of composites using COS and CG as matrix with banana and sugarcane bagasse fibers under controlled temperature and pressure. While stress-strain curves of the matrix material were found to be typical of thermoplastics, those of composites showed a smaller plastic region. Young's modulus, yield strength, ultimate tensile strength and strain at break obtained were found to be different from those reported earlier that were obtained by manual method. The values of these properties for matrix were found to be lower than those reported earlier for similar matrix. However, the values for the above properties in the composites (prepared with this matrix) were found to be higher than those obtained under manual conditions. These results are explained by the fractographic studies, which revealed good fiber/ matrix adhesion.
\end{abstract}

Keywords: Polymer-matrix composites (PMCs); Castor oil cake; Starch; Plant fibers; Mechanical properties; Microstructures; Compression molding

\section{Introduction}

The polymer composite industry desires to obtain novel agrobased materials at affordable costs to replace expensive and nondegradable synthetic polymers and fibers. Besides, ever expanding search for new high performance materials from natural sources has compelled studies to assess and characterize green product based composites. This is essential, particularly in the case of renewable agro industrial resources, because their chemical composition, which in turn dictates their properties, depends on many factors such as geographical conditions, soil conditions, age of the plants, etc. [1,2]. The utilization of agro-based materials for development of composites could contribute as non-food sources for economic growth of the rural areas in developing countries. There are several reports, including indepth and state of the art reviews, on characterization of plant-based materials such as starches and lignocellulosic fibers. These highlight systematic studies carried out both in Brazil and other places on the utilization of these materials for the preparation of composites [349]. Of these, particular interest is of starch based 'green' composites, which have been extensively investigated [22,29-32,35,38-43]. These studies have focused predominantly on utilizing locally available renewable materials as the resource to develop commercially viable and environmentally acceptable composite materials. These efforts are expected to contribute with the sustainable development of the modern society while opening up a new area for value-added products that still present new challenges for materials scientists, design engineers and technologists. These studies address the global concern for recycling of agro-industrial byproducts. In this endeavor, agro industrial byproducts such as castor oil cake (obtained from oil industry) and 'crude' glycerin (obtained by the trans-esterification reaction during the biodiesel production), plant fibers such as fibers of banana and sugarcane bagasse have a huge potential that needs to be exploited for further applications.
Overall objective of the authors has been to formulate new and attractive propositions to explore the use of the above mentioned materials (castor oil cake and 'crude' glycerin) through composite technology. Preliminary studies have been carried out by the authors on the preparation of composites using these materials manually (with no control on pressure and temperature) and their characterization [30]. Based on the results obtained, it was found necessary to prepare the composites under controlled conditions and characterize them to achieve the best mechanical properties. Accordingly, this paper presents the processing of castor oil cake, 'crude' glycerin and fibers from banana plant and sugarcane bagasse using thermo-molding method under controlled conditions of pressure and temperature. Obtained composites were evaluated for tensile properties through their stress-strain curves. The measured properties are discussed on the basis of fractographic studies that were carried out using Scanning Electron Microscope (SEM). The prepared composites can substitute the Medium Density Fiberboards (MDF) in some sectors such as furniture, automotive (parcel shelves, door panels, instrument panels, armrests, headrests) and building/construction. It is also hoped that the obtained results may provide designers with new alternate materials for wood based products to meet the challenging requirements of new potential applications.

*Corresponding author: Kestur Gundappa Satyanarayana, Honorary Professor, Poornaprajna Scientific Research Institute, (PPISR), Bidalur Post, Devanahalli, Bangalore-562 110, Karnataka, India, Tel: +91-80-266-601-40; E-mail: gundsat42@hotmail.com

Received November 12, 2014; Accepted December 24, 2014; Published December 29, 2014

Citation: Guimarães JL, Cursino ACT, Saul CK, Sierrakowski MR, Ramos LP (2014) Effect of Processing Conditions on Tensile Properties of Green Composites of Castor Oil Cake Starch-Plant Fibers. J Bioprocess Biotech 5: 198 doi: 10.4172/2155-9821.1000198

Copyright: (C 2014 Guimarães JL, et al. This is an open-access article distributed under the terms of the Creative Commons Attribution License, which permits unrestricted use, distribution, and reproduction in any medium, provided the original author and source are credited. 


\section{Experimental}

\section{Materials}

The castor bean oil cake (CBC) used in the present study was supplied by the Azevedo Oils Industrial and Commerce Ltd. (Brazil). This material had a $\mathrm{pH}$ of 6.5 when (it was) mixed with water in the ratio of 1:10 proportion. The details of the constituents of $\mathrm{CBC}$ have been reported earlier [30]. This material was used as the starch matrix with glycerol as plasticizer in view of its high content of protein and organic matter.

Recovered glycerin, the byproduct of biodiesel industry, referred to here after as 'Crude Glycerin' (CG) or 'Recovered Glycerin' (RG) was supplied by Technological Institute of Paraná (TECPAR). Such fraction was derived from soybean oil ethanolysis using sodium hydroxide as the reaction catalyst precursor as mentioned elsewhere [25]. The composition of this RG fraction has been reported earlier $[25,30]$.

Banana fibers and sugarcane bagasse (here after also called "bagasse fibers"), used as reinforcements in this study, were obtained and conditioned as explained earlier [30]. Briefly, a banana plant was cut into small logs from which sheaths were taken out. The fibers, obtained manually from these sheaths by scraping with knife, were dried in the sun for about five days. The bagasse fibers were obtained from a local ethanol manufacturing industry.

\section{Methods}

\section{Preparation of composites}

As the moisture content influences the mechanical properties of composites, moisture content of all the raw materials (both the matrices and the composites) were determined before preparing the laminates. Details of the preparation of castor oil cake and both banana and bagasse fibers as well as the composites using these and the crude glycerin are reported earlier [30]. Briefly, the as-received $\mathrm{CBC}$ was first dried for 72 hours at $65^{\circ} \mathrm{C}-70^{\circ} \mathrm{C}$ in a hot air oven, followed by milling into powder. The milling was done sequentially, first in a vibratory mill followed by a ball mill. This material was then dried in an oven at $85^{\circ} \mathrm{C}$ for $24 \mathrm{~h}$ and sieved to separate it into three portions, namely above 80 mesh size, 40-80 mesh and below or equal to 40 mesh size. Size analysis of sieved powder revealed that $6.8 \%$ of the powder was above 80 mesh size, $11.2 \%$ was within $40-80$ mesh size and about $82 \%$ was below or equal to of 40 mesh size. In view of larger portion of the powder (below 40 mesh size) was used as the matrix in the preparation of composites.

Both banana and bagasse fibers were first oven dried at $65^{\circ} \mathrm{C}$ $70^{\circ} \mathrm{C}$ for $72 \mathrm{~h}$, followed by milling for $1-3 \mathrm{~h}$ in a vibratory ball mill to obtain fibers of uniform length $(1.5-3 \mathrm{~mm})$. This was done with a view to compare the properties of the composites with these fibers with manually produced similar composites reported previously [30]. Based on the earlier experience of the authors with the use of these materials, banana fibers with $67-300 \mu \mathrm{m}$ average diameter and $1.5 \mathrm{~mm}$ length and bagasse fiber with 200-320 $\mu \mathrm{m}$ average diameter and 1.5-3.0 mm average length [30] were chosen for the preparation of composites. These fibers were dried again at $60^{\circ} \mathrm{C}$ for $24 \mathrm{~h}$ prior to composite preparation. These fibers, when used in the composites, were designated as 'BF' (Banana Fiber) and 'SBF' (Bagasse Fiber) respectively.

Matrix and composite laminates were prepared under temperature and pressure controls as described below based on the earlier experience (ease of processing, sample homogeneity obtained using a mixture of castor oil cake, corn starch and 30\% RG) [30]. This amount of the plasticizer was suggested as ideal for processing and therefore it was decided to use the same amount of recovered glycerin in the subsequent composite preparations.

The matrix laminates, using $\mathrm{CBC}$ and Recovered Glycerol (RG) in the ratio of 70:30, were prepared by mixing the cake and RG using two types of mixers, a ball mill and a mechanical mixer with a steel vat and blades. After homogenizing, this mixture was poured into a $220 \mathrm{~mm}$ $\times 220 \mathrm{~mm}$ 316L stainless steel mold and subjected to thermo-molding using a SOLAB hydraulic press that has with both temperature and pressure controls. The pressure range used was between 4 and 9 tons (200-350 $\left.\mathrm{kgf} / \mathrm{cm}^{2}\right)$ and the temperature range was between $140^{\circ} \mathrm{C}$ to $190^{\circ} \mathrm{C}$. Thermocouples in each mold plate were used to measure the temperature, which was maintained within $\pm 3^{\circ} \mathrm{C}$ of the specified molding temperature. Initially, the mixture in the mold was slowly heated to $160^{\circ} \mathrm{C}$ at a rate of $10^{\circ} \mathrm{C} / \mathrm{min}$, kept at $160^{\circ} \mathrm{C}$ for $3 \mathrm{~min}$ and then it was allowed to cool to room temperature. Thus, $120 \mathrm{~mm} \times 120$ $\mathrm{mm} \times 25 \mathrm{~mm}$ laminates were obtained for further analysis.

In the case of composites, sieved fractions of each fiber (25-35\%) was added to the matrix mixtures containing $\mathrm{CBC}(35-45 \%)$ and $30 \%$ of RG and homogenously mixed in a metallic container using a mechanical mixer. This composite mixture was transferred to the stainless steel molds and pressed as mentioned above.

All the laminates prepared as mentioned above are listed in Table 1 showing composition and proportions of components. All the samples were equilibrated after the preparation, by keeping them in desiccators (RH 40-50 \%) before subjecting them for further evaluations.

\section{Tensile Testing of composites}

Tensile samples were cut according to the ASTM standard D $638 \mathrm{M}$ for both the matrix and composites using a $\mathrm{CO}_{2}$ laser cutter GRAVOGRAPH LS-100 (30 W) with a cutting speed of $0.5 \mathrm{~mm} \cdot \mathrm{min}^{-1}$. Tensile tests on matrix as well as on composite samples were carried out using a Universal Testing Machine EMIC (DL-2000) and INSTRON (Model - 5960), using a $5 \mathrm{kN}$ load cell and speed of $1 \mathrm{~mm} /$ min, according to the ASTM D-638 standard. Two different machines were used for comparison. A minimum of 5 samples were used for each test, except for tensile strength testing, where 3 samples each were used. Average values obtained for each test was used for the interpretation of the obtained experimental results.

\section{Fractographic Studies of composites}

Tensile tested samples of thermoplastic matrix of $\mathrm{CBC}$ and $\mathrm{RG}$ and their composites with banana and sugar cane bagasse fibers were sputter coated with gold to enable them to be observed in a JEOL Scanning Electron Microscope [SEM] using 15keV.

\section{Results and Discussion}

\section{Tensile properties}

Typical stress-strain curves of thermoplastic matrix of $\mathrm{CBC}$ and RG and two of its composites, one with banana

fiber and the other with sugarcane bagasse fiber ( 25 wt.\% each), are shown in Figure 1. It can be seen that Figure 1(a) indicates typical plastic- elastic behavior of a thermoplastic matrix material, while those of composites with lignocellulosic fibers (Figure 1(b) \& (c) showed a smaller plastic region. The later ones (small plastic regions) were expected in view of the presence of reinforcing fibers. Further, the stress-strain curves also showed decreasing strains at higher breaking 
Citation:Guimarães JL, Cursino ACT, Saul CK, Sierrakowski MR, Ramos LP (2014) Effect of Processing Conditions on Tensile Properties of Green Composites of Castor Oil Cake Starch-Plant Fibers. J Bioprocess Biotech 5: 198 doi:10.4172/2155-9821.1000198

Page 3 of 8

\begin{tabular}{|c|c|c|}
\hline Sample & Constituents of Matrix (\%) & Reinforcing Fiber (\%) \\
\hline C70 RG30 & 70 Castor oil Cake(MST)-30 Recovered Glycerol & -Nil- \\
\hline C45RG30B25 & 45 Castor oil Cake-30 Recovered Glycerol & 25 Banana Treated (BT) \\
\hline C40RG30B30 & 40 Castor oil Cake-30 Recovered Glycerol & 30 Banana Treated (BT) \\
\hline C35RG3035B & 35 Castor oil Cake-30 Recovered Glycerol & 35 Banana Treated (BT) \\
\hline C45RG30SB25 & 45 Castor oil Cake-30 Recovered Glycerol & 25 Bagasse Treated (SBT) \\
\hline C40RG30SB30 & 40 Castor oil Cake-30 Recovered Glycerol & 30 Bagasse Treated (SBT) \\
\hline C35RG30SB35 & 35 Castor oil Cake-30 Recovered Glycerol & 35 Bagasse Treated (SBT) \\
\hline
\end{tabular}

C: Castor oil cake; RG: Recovered/Crude glycerol; B: Banana fiber; SB: Sugarcane bagasse

Table 1: Details of Matrix and Composite Samples prepared in this work
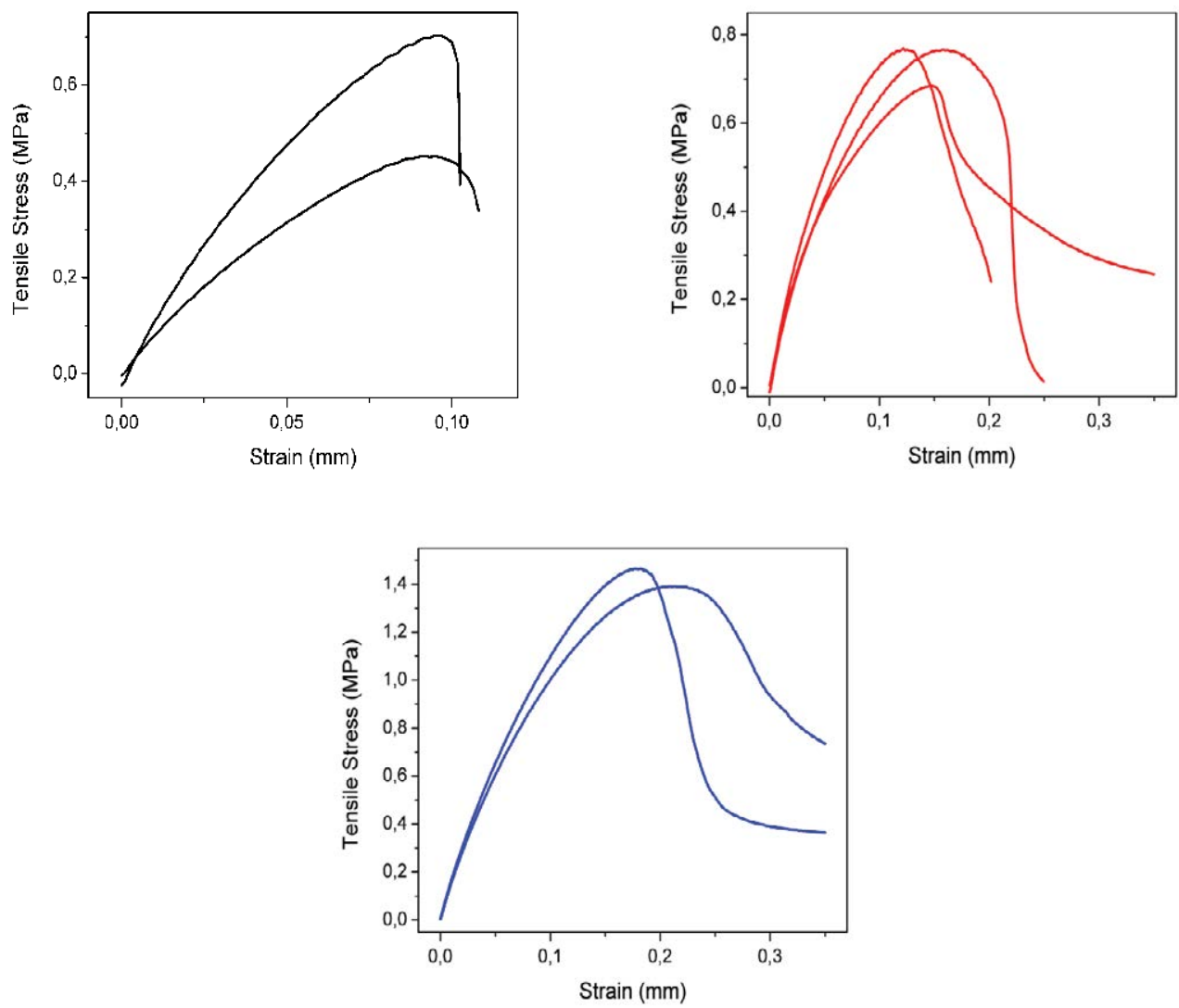

Figure 1: Stress-Strain Curves of (a)-Castor oil cake+ Recovered Glycerol; (b)- Castor oil cake+ Recovered Glycerol +25\% Banana Fiber and (c)- Castor oil cake+ Recovered Glycerol $+25 \%$ Bagasse Fiber.

loads. The breaking load was higher for bagasse fiber composite than that for banana fiber composite. In fact, one can see the stress-strain curves of bagasse fiber containing composites tend to flatten a little until the fracture of the composites. This behavior may be understood as due to the sliding of the matrix on the fibers, and some matrix may stay on the fibers (coating of the fiber) resisting the final fracture. This was supported by the SEM studies as seen in methods section later (Figure 1).

Values of Young's Modulus (YM), Ultimate Tensile Strength (UTS), Yield Strength (YS) and \% elongation of all the tested materials have been derived from the curves above. They are tabulated in Table 2.

It can be seen from the table that the values of tensile properties (YM, UTS, YS and \% strain at break) of both the matrix and its composites are different from those obtained using manual conditions reported earlier. This can be attributed to the use of controlled conditions rather than the manual conditions as reported in the earlier studies [30]. The matrix of castor oil cake with recovered glycerol exhibited higher Young's modulus value (389 $\mathrm{MPa}$ ) than that of matrix prepared by manual method $(27.07 \mathrm{MPa})$. This value is about 12.5 times higher than that of $70 \%$ corn starch with $30 \%$ pure glycerol composite $(24.68 \mathrm{MPa})$ that was prepared by a similar method [30] indicating higher stiffness of the CBC compared to corn starch. Similarly, value of yield strength (YS: $0.58 \mathrm{MPa}$ ) of the composite prepared under controlled conditions is almost similar $(0.52 \mathrm{MPa})$ to that obtained under manual conditions.

On the other hand, the values of Ultimate Tensile Strength (UTS: $0.51 \mathrm{MPa}$ ) and \% strain at break of this matrix (0.32) are lower than those (of matrix) prepared by manual method [UTS: $0.70 \mathrm{MPa}$ and $\%$ Strain at Break: 3.14]. Differences in UTS and \% strain at break between the two methods of preparation indicate that this matrix under 
Citation:Guimarães JL, Cursino ACT, Saul CK, Sierrakowski MR, Ramos LP (2014) Effect of Processing Conditions on Tensile Properties of Green Composites of Castor Oil Cake Starch-Plant Fibers. J Bioprocess Biotech 5: 198 doi:10.4172/2155-9821.1000198

Page 4 of 8

\begin{tabular}{|c|c|c|c|}
\hline Sample & Young Modulus (MPa) & Yield Strength (MPa) & Ultimate Tensile Strength (MPa) \\
\hline C70 RG30 (Manual) & 27.07 & 0.52 & 0.70 \\
\hline C70 RG30 & $389.20 \pm 31.6$ & $0.58 \pm 0.17$ & $0.51 \pm 0.13$ \\
\hline C45RG30B25 & $417.9 \pm 31.60$ & $0.74 \pm 0.20$ & $0.65 \pm 0.02$ \\
\hline C40RG30B30 & $485.3 \pm 31.6$ & $1.20 \pm 0.04$ & $1.11 \pm 0.16$ \\
\hline C45RG30SB25 & $595.8 \pm 50.4$ & $1.47 \pm 0.43$ & 1.51 \\
\hline C40RG30SB30 & $462.7 \pm 12.4$ & $1.43 \pm 0.36$ & 1.47 \\
\hline
\end{tabular}

C: Castor oil cake; RG: Recovered/Crude Glycerol; B: Banana fiber; SB: Sugarcane bagasse Fiber

Table 2: Tensile properties of Castor oil cake-recovered glycerol and banana fiber/sugarcane bagasse green composites

controlled conditions presents better adhesion with the fibrous content of the $\mathrm{CBC}$ itself. In fact, the fibrous content is originated during the crushing process and separation of the castor oil and is found to be approximately $13 \%$ [23]. The adhesion is probably related to more effective interactions arising due to hydrogen bonding interactions in the silicate groups. Thus, the matrix obtained under controlled conditions is quite rigid, but slightly brittle (Table 2).

In the case of composites prepared under controlled conditions, the incorporation of banana and bagasse fibers increased all the tensile properties over those of matrix laminates prepared in identical conditions. The values obtained are YM: 303-595MPa; YS: $0.74-$ $1.47 \mathrm{MPa}$, UTS: $0.65-1.36 \mathrm{MPa}$ and $\%$ strain at break: $1.43-1.78$. These values indicate a good adhesion between the fibers and the matrix, independent of fiber type used and presence of fibrous material in the castor oil cake itself as mentioned above.

The latter is originated during the crushing process and separation of the castor oil. Presence of fibrous material in CBC is evident in the SEM photographs. Further, it can also be observed in Table 2 that the values of YM increase with increasing amount of banana fibers [from about $418 \mathrm{MPa}$ for $25 \%$ fiber content to about $596 \mathrm{MPa}$ for 35\% fiber content]; however, the YM values decreased in the case of bagasse fibers [from about $463 \mathrm{MPa}$ for 25\% fiber content to $303 \mathrm{MPa}$ for 35\% fiber content. This may probably be due to the following: (i) better interaction of banana fibers with the matrix even with higher fiber content due to the hydrophilic nature of the banana fibers as shown in thermal studies [30]; (ii) behavior of open nature of banana fibers during compression leading to non-homogeneous distribution of fibers in the composite samples compared to compact nature of bagasse fibers, which leads to homogenous distribution [47]. Nevertheless, it can also be seen that the values of YM and UTS of composites with $25 \%$ wt. content of both banana fiber and sugar cane fiber are inferior to those observed for composites of the same fiber contents with corn starch plasticized with pure glycerol matrix prepared under similar conditions. This is evident from the following: Values of tensile properties of composites with $25 \%$ wt. content of both banana fiber and sugar cane fiber are YM: about $418 \mathrm{MPa}$ and UTS: $0.65 \mathrm{MPa}$ and YM: $303 \mathrm{MPa}$ and UTS: 1.32 MPa respectively, while the values of tensile properties of composites of the same fiber contents with corn starch plasticized with pure glycerol matrix reported [30] are: YM: about $484.04 \mathrm{MPa}$, UTS: $4.34 \mathrm{MPa}$ and YM: 468.28 MPa and UTS: 3.85 MPa respectively, for banana fiber and bagasse fiber containing composites

The values of breaking strain of all the CBC based composites remained almost constant [about 1.4-1.8\%] with increasing fiber content in the case of both types of composites. However, except for $25 \%$ banana fiber containing CBC composite the values of strain at break for all the composites were lower than those of matrix of corn starch with pure glycerol prepared under similar conditions [10-15\%].

\section{Fractographic studies of castor bean cake and its composites}

Figure 2 shows the presence of small fibers in the raw castor oil cake (about 13\%), which increased the interaction of the castor oil cake starch matrix with the fibers (banana or sugarcane bagasse fibers) that were added to it and this improved the tensile properties of the composites.

Figures 3a-3f show comparison of SEM photographs of morphologies (Fractographs) of samples of tensile testing of thermoplastic matrix of $70 \%$ CBC and 30\% RG matrix samples with those of $70 \%$ corn starch and $30 \%$ pure glycerin matrix at three different magnifications. It may be noted that many of the images shown here were taken at the proper magnification for each feature and hence they may not be having the same magnifications. All images were taken after focusing on a central feature at very high magnification. As can be seen from the figures $3 \mathrm{a}-3 \mathrm{f}$, there are some regions which are out of focus, due to the sample topography. In some samples height fluctuation exceeds by far the SEM depth of focus.

In general, these photographs show that both the matrices are typical of a starchy material containing some fibers in it. However, the surface of thermoplastic matrix of CBC and RG (Figure 3d) differs from that of thermoplastic matrix of corn starch and $\mathrm{G}$ (pure glycerol) (Figure 3a) or RE (Recovered glycerol) reported earlier [26]. As can be seen from the figure the fracture surface is more irregular in the former matrix. This suggests that the recovered glycerol reacts with the starch present in the castor bean cake. Further, the fracture surface of thermoplastic matrix of corn starch and pure glycerin (Figures 3a3c) shows a good homogeneity. There is absence of starch granules. Besides, there is no indication of any reaction in the structure, but for the presence of narrow cracks, characteristic of this type of matrix. It

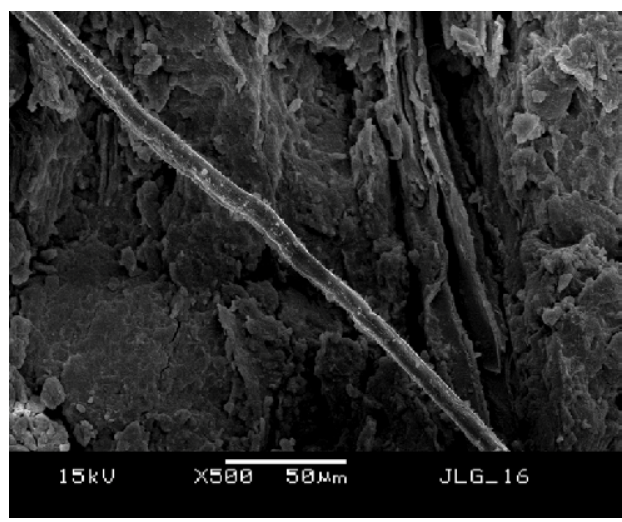

Figure 2: Transverse Section Facture Surface of Tensile Tested $70 \%$ Castor Oil Cake $+30 \%$ Recovered Glycerol. 
Citation:Guimarães JL, Cursino ACT, Saul CK, Sierrakowski MR, Ramos LP (2014) Effect of Processing Conditions on Tensile Properties of Green Composites of Castor Oil Cake Starch-Plant Fibers. J Bioprocess Biotech 5: 198 doi:10.4172/2155-9821.1000198

Page 5 of 8
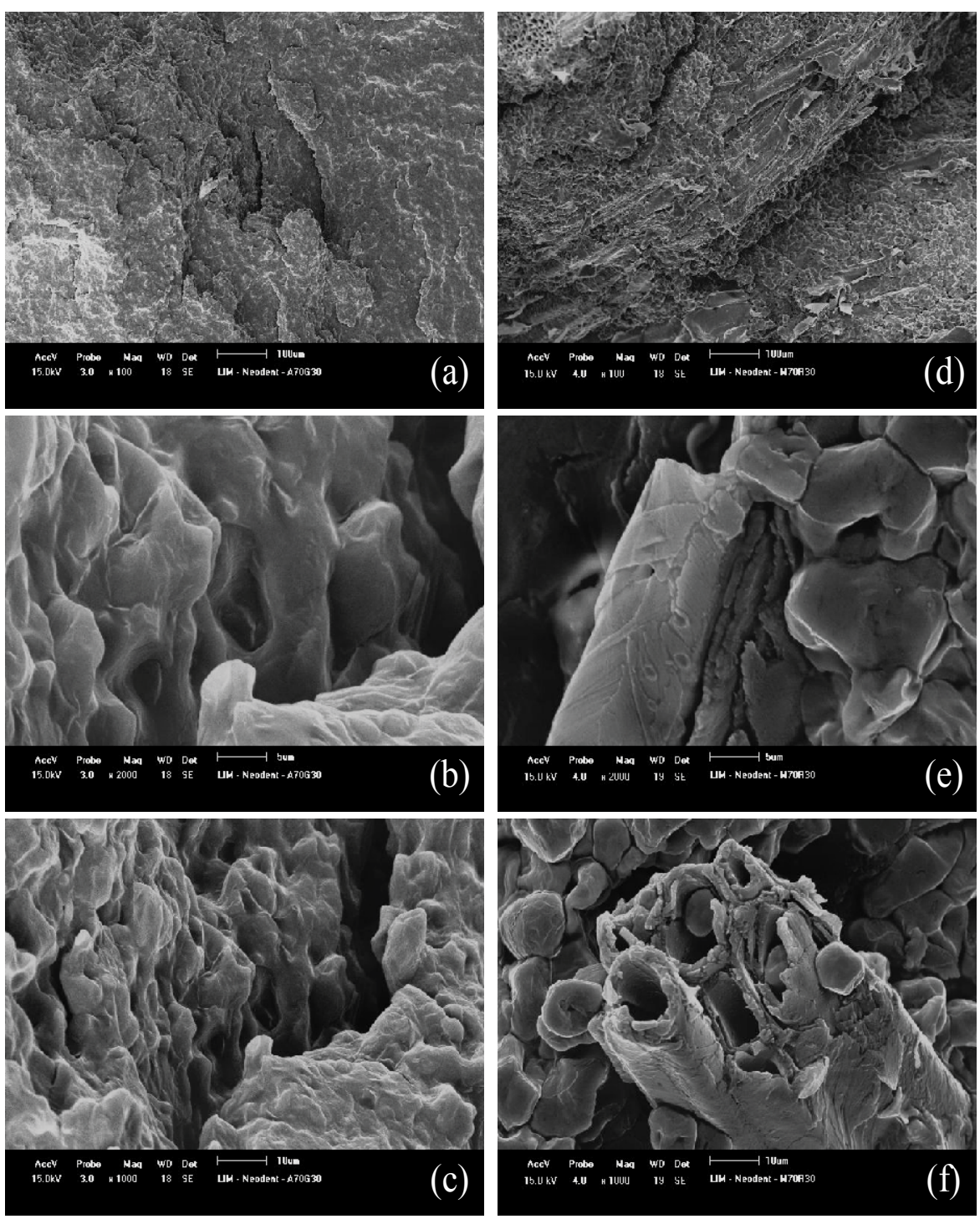

Figure 3: Scanning Electron Micrographs of: (a-c)- Corn Starch+ Pure Glycerin and (d-e)- Castor Oil Cake+ Recovered Glycerol showing the Fracture Surfaces at different magnifications (100X, 500x and 1000x).

appears that there was less number of cracks along with reduction in their width in relation to the ones observed in the manual method [30]. This suggests that the glycerol penetrates the starch granules and due to the additional action of temperature, a stronger hydrogen bonding network is formed resulting in plasticized starch [48].

The fractured surface of thermoplastic matrix of $\mathrm{CBC}$ and $\mathrm{RG}$ (Figures 3d-3f), on the other hand, show some fibers from the castor oil seeds, which are completely coated by the plasticized starch. This suggests that the RG reacts with the $25 \%$ starch present in the $\mathrm{CBC}$ [26]. Also, there were differences in the fractured surfaces of both these matrices in relation to the latter (thermoplastic matrix of CBC and RG) showing a slightly more irregular surface when compared to that of the former (i.e., thermoplastic matrix of $\mathrm{CBC}$ and $\mathrm{G}$ ). The good interaction between $\mathrm{CBC}$ matrix and the fibers contained in this residue could be due to the presence of existent silicon groups [as silanes], on the surface of the fibers.

The fractured surfaces of composites of thermoplastic matrix of $\mathrm{CBC}$ and RG containing 30\% wt. sugarcane bagasse and 30\% wt. banana fibers are shown in Figures $4 \mathrm{a}-4 \mathrm{c}$ and Figures $4 \mathrm{~d}-4 \mathrm{f}$ respectively. In general, the fractured surface of both the composites reveals good adhesion with the matrix. This is evident by the presence of fiber pull out on the fractured surface of composites (Figures $4 \mathrm{a}$ and $4 \mathrm{~d}$ ).

However, the non-existence of a gap between the fiber and the matrix also suggests good interfacial bonding [49]. When the adhesion is strong, the fibers break parallel to the surface of the fracture $[49,50]$. This is further supported by the absence of any residue observed on the fractured surface of these composites (Figures $4 \mathrm{a}$ and $4 \mathrm{~d}$ ) indicative of poor adhesion in the in the fiber / matrix interface $[49,51]$.

It may be concluded that the thermoplastic matrix of $\mathrm{CBC}$ and $\mathrm{RG}$ gives good adhesion with both fibers that were used and therefore it can be used as a matrix substitute for thermoplastic matrix of corn starch and pure glycerin.

In the case of composites of thermoplastic matrix of $\mathrm{CBC}$ and $\mathrm{RG}$ 
Citation:Guimarães JL, Cursino ACT, Saul CK, Sierrakowski MR, Ramos LP (2014) Effect of Processing Conditions on Tensile Properties of Green Composites of Castor Oil Cake Starch-Plant Fibers. J Bioprocess Biotech 5: 198 doi:10.4172/2155-9821.1000198

Page 6 of 8
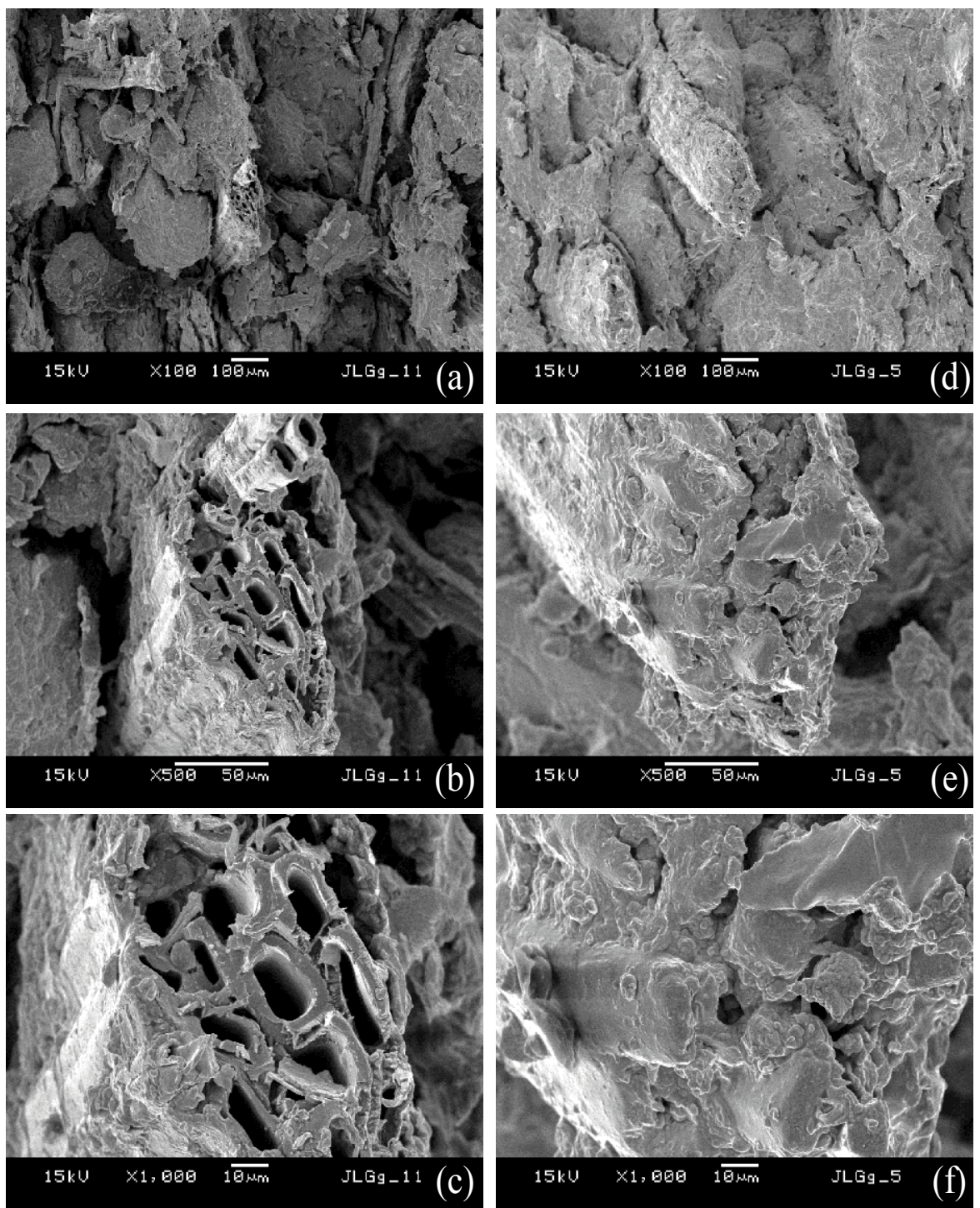

Figure 4: Scanning Electron Micrographs of (a-c): 40\% Castor Oil Cake + 30\% Recovered Glycerol + 30 Banana Fiber; (b-d): 40\% Castor Oil Cake + 30\% Recovered Glycerol+ 30 Sugarcane Bagasse Fiber at different magnifications.

containing 30\% bagasse fiber, a different type of fracture was observed. In this case, a more wrinkled surface than that of $30 \%$ banana fiber composites was evident compared to that of the composite with $30 \%$ banana fiber. This may be due to the different fiber dimensions used. Also, a more uniform fiber distribution and better fiber orientation is observed in the case of bagasse fiber composites compared to those made with banana fiber. According to Sousa et al. [52], such orientations are common in composites produced with pressures above $6 \mathrm{MPa}$. In addition, the top of the bagasse fibers was covered by the matrix (Figures 4e and 4f), in contrast to what was observed in composites of corn starch and RG or pure glycerol containing bagasse fiber [30].

Another feature of castor oil cake based matrix materials is the fractured matrix surface as observed in the matrix of $\mathrm{CBC}$ and $\mathrm{RG}$ (Figures $4 \mathrm{a}-4 \mathrm{c}$ ). This showed dark brown colorations sometimes tending to black and a smell resembling brown sugar. In addition to the type of starch present in the castor oil cake (ash color due to drying, ripening and extraction), this is certainly due to properties and chemical composition of crude glycerin, which is dark yellow to brown due to contaminations coming from the biodiesel production. These observations are in agreement with earlier descriptions [53]. The fractured surfaces of the composites also revealed a dark brown color indicating the effect of fibers on the morphology of the matrix. However, it may be noted that the morphology of the composite is dictated by the fiber content and its type and not by the matrix. This can be seen in the above figures and is in agreement with the observations of Choi et al. [53]. The presence of pores and large number of wider channels may be due to the evaporation of undesirable matrix components during thermal processing (Figure $4 \mathrm{~d}$ ). Also, this heterogeneity can be partially attributed to the presence of a second phase in the somewhat globular structures found in the fractured surface.

\section{Conclusions}

- Tensile properties (Young's modulus, ultimate tensile 
strength, yield strength and \% strain at break) of both the matrix of castor oil cake with recovered glycerol and its composites with banana/ sugarcane bagasse fibers prepared under controlled conditions are found to be different from those of composites prepared by manual conditions that was reported earlier by the authors. This is due to the change in the methodology adopted in preparing the thermoplastic matrix and its composites.

- Incorporation of banana and bagasse fibers increased all the tensile properties (YM: 303-595 MPa; YS: 0.74-1.47 MPa, UTS: 0.65-1.36 MPa and \% strain at break: 1.43-1.78) over those of matrix laminates (YM: $389 \mathrm{MPa}$, YS: $0.58 \mathrm{MPa}$, UTS: $0.51 \mathrm{MPa}$ and \% strain at break: 0.32 ) prepared under identical conditions. This indicates a good adhesion between the fibers and the matrix independent of fiber type used and presence of fibrous material in the castor oil cake itself as revealed by fractographic studies.

- In the case of composites, YM increased with increasing amount of banana fibers [from about $418 \mathrm{MPa}$ for $25 \%$ fiber content to about $596 \mathrm{MPa}$ for $35 \%$ fiber content], while it decreased in the case of bagasse fibers [from about $463 \mathrm{MPa}$ for $25 \%$ fiber content to $303 \mathrm{MPa}$ for $35 \%$ fiber content]. This could be due to good interaction of banana fibers with the $\mathrm{CBC}$ and RG matrix even with higher fiber content compared to that of bagasse fibers.

- The starch-containing castor oil cake and the crude glycerin from ethanolysis gave good fiber adhesion properties and could be used as a matrix substitute for any starch such as corn starch and pure glycerol.

\section{Acknowledgements}

The authors sincerely thank Mr. Leonardo Biancollini of Electrolux, Mr. Fabio Tomczak and Dr. Gregorio G.C. Arizaga for their help in tensile testing, analysis of the data and help in various stages of the preparation of this paper, respectively. They also thank CME/UFPR - Centro de Microscopia Eletrônica for the scanning electron microscopic studies, José Eduardo F. C. Gardolinski of Laboratory of Minerals and Rocks Analysis of the Department of Geology of UFPR (LAMIRUFPR) for the TGA/DTA measurements, Physics Department of UFPR for the X-ray diffraction measurements and Corn Products Brazil for supplying the starch samples. The authors also acknowledge the financial support of CNPq, FINEP and Araucaria Foundation. Reading of the manuscript, editing and suggestions to improve the flow of the text by Prof. Anupama R, Professor and HOD, Department of Pharmaceutical Chemistry, Vivekananda College of Pharmacy, Bangalore (India) is sincerely acknowledged. The authors also acknowledge the financial support of CNPq, FINEP and Araucaria Foundation.

\section{References}

1. Rowell RM, Han JS, Rowell JS (2000) Characterization and factors effecting fiber properties. Natural Polymers and Agrofibers Composites 115-134.

2. Bessadok A, Marais S, Roudesli S, Lixon C, Metayer M (2008) Influence of chemical modifications on water-sorption and mechanical properties of Agave fibres. Composites Part A: Applied Science and Manufacturing 39: 29-45.

3. Puglia, D, Tomassucci A, Kenny JM (2003) Processing, properties and stability of biodegradable composites based on Mater-Bi ${ }^{\circledR}$ and cellulose fibres. Polym Adv Technol 14: 749-756.

4. Alvarez VA, Terenzi A, Kenny JM, Vazquez A (2004) Melt rheological behavior of starch-based matrix composites reinforced with short sisal fibers. Polym Eng Sci 44: 1907-1914.

5. Takagi H, Ichihara $\mathrm{Y}$ (2004) Effect of fiber length on mechanical properties of "Green" composites using a starch-based resin and short bamboo fibers. JSME International Journal Series A Solid Mechanics and Material Engineering 47 $551-555$.

6. Mathew AP, Oksman K, Sain M (2005) Mechanical properties of biodegradable composites from poly lactic acid (PLA) and microcrystalline cellulose (MCC). J Appl Polym Sci 97: 2014-2025.

7. Shibata S, Cao Y, Fukumoto I (2005) Press forming of short natural fiberreinforced biodegradable resin: Effects of fiber volume and length on flexural properties Polym Testing 24: 1005-1011.
8. Lee SH, Wang S (2006) Biodegradable polymers/bamboo fiber biocomposite with bio-based coupling agent. Composites Part A: Applied Science and Manufacturing 37: 80-91.

9. Mohanty AK, Misra M, Drzal LT (2002) Sustainable bio-composites from renewable resources: opportunities and challenges in the green materials world. J Polym Environ 10: 19-26

10. Bogoeva-Gaceva G, Avella M, Malinconico M, Buzarovska A, Grozdanov A, et al. (2007) Natural fiber eco-composites. Polym Compos 28: 98-107.

11. Gomes A, Matsuo T, Goda K, Ohgi J (2007) Development and effect of alkali treatment on tensile properties of curaua fiber green composites. Composites Part A: Applied Science and Manufacturing 38: 1811-1820.

12. Nair LS, Laurencin CT (2007) Biodegradable polymers as biomaterials. Prog Polym Sci 32: 762-798.

13. Teixeira EM (2007) Use of cassava starch for the preparation of new thermoplastic materials (Utilização de amido de mandioca na preparação de novos materiais termoplásticos), Ph.D. Thesis, University of São Paulo, Brazil. (In Portuguese)

14. Torres FG, Arroyo OH, Gomez C (2007) Processing and Mechanical properties of natural fiber reinforced thermoplastic starch biocomposites. J Thermoplastic Compos Mater 20: 207-223.

15. Liu Z, Erhan SZ (2008) Green composites and nanocomposites from soybean oil. Mater Sci Eng A 483-484: 708-711.

16. John MJ, Thomas S (2008) Biofibers biocomposites. Carbohyd Polym 71: 343-364

17. Shibata S, Cao Y, Fukumoto I (2008) Flexural modulus of the unidirectional and random composites made from biodegradable resin and bamboo and kenaf fibres. Composites Part A: Applied Science and Manufacturing 39: 640-646.

18. Singh S, Mohanty AK, Sugie T, Takai Y, Hamada H (2008) Renewable resource based biocomposites from natural fiber and polyhydroxybutyrate-co-valerate (PHBV) bioplastic. Composites Part A: Applied Science and Manufacturing 39 875-886.

19. Takagi H, Asano A (2008) Effects of processing conditions on flexural properties of cellulose nanofiber reinforced "green" composites. Composites Part A: Applied Science and Manufacturing 39: 685-689.

20. Shih YF, Huang CC, Chen PW (2008) Biodegradable green composites reinforced by the fiber recycling from disposable chopsticks. Mater Sci Eng $A$ 527: 1516-1521.

21. Ashori A (2008) Wood-plastic composites as promising green-composites for automotive industries! Bioresour Technol 99: 4661-4667.

22. Famá L, Gerschenson L, Goyanes S (2009) Starch-vegetable fiber composites to protect food products. Carbohyd Polym 75: 230-235.

23. Huang X, Netravali A (2009) Biodegradable green composites made using bamboo micro/nano-fibrils and chemically modified soy protein resin. Compos Sci Technol 69: 1009-1015.

24. Pinto CES, Gregorio GCA, Fernando W, Ramos LP, Satyanarayana KG (2009) Studies of the effect of molding pressure and incorporation of sugarcane bagasse fibers on the structure and properties of poly (hydroxy butyrate) Composites Part A: Applied Science and Manufacturing 40: 573-582.

25. Satyanarayana KG, Gregorio GCA, Fernando W (2009) Biodegradable composites based on lignocellulosic fibers-An overview. Prog Polym Sci 34: 982-1021.

26. Vanderleia A (2009) Obtaining thermoformed composite from the plasticized castor cake with glycerol derived from the transesterification process oils and fats. Federal University of Parana (UFPR), Curitiba, Paraná, Masters' Thesis. (In Portuguese)

27. Athijayamani A, Thiruchitrambalam M, Natarajan U, Pazhanivel B (2009) Effect of moisture absorption on the mechanical properties of randomly oriented natural fibers/polyester hybrid composite. Mater Sci Eng A 517: 344-353.

28. Graupner N, Hermann AS, Müssig J (2009) Natural and man-made cellulose fibre-reinforced poly (lactic acid) (PLA) composites: An overview about mechanical characteristics and application areas. Composites Part A: Applied Science and Manufacturing 40: 810-821.

29. Debiagi F, Mali S, Grossmann MVE, Yamashita F (2010) Effects of vegetal fibers on properties of cassava starch biodegradable composites produced by extrusion. Ciencia e Agrotecnologia 34: 1522-1529. 
Citation:Guimarães JL, Cursino ACT, Saul CK, Sierrakowski MR, Ramos LP (2014) Effect of Processing Conditions on Tensile Properties of Green Composites of Castor Oil Cake Starch-Plant Fibers. J Bioprocess Biotech 5: 198 doi:10.4172/2155-9821.1000198

30. Guimarães JL, Wypych F, Saul CK, Ramos LP, Satyanarayana KG (2010) Studies of the processing and characterization of corn starch and its composites with banana and sugarcane fibers from Brazil. Carbohyd Polym 80: 130-138.

31. Kaushik A, Singh M, Verma G (2010) Green nanocomposites based on thermoplastic starch and steam exploded cellulose nanofibrils from wheat straw. Carbohyd Polym 82: 337-345.

32. Woehl MA, Canestraro CD, Mikowski A, Sierakowski MR, Ramos LP, et al (2010) Bionanocomposites of thermoplastic starch reinforced with bacteria cellulose nanofibres: Effect of enzymatic treatment on mechanical properties. Carbohyd Polym 80: 866-873.

33. Xie Y, Hil CAS, Xiao Z, Militz H, Mai C (2010) Silane coupling agents used for natural fiber/polymer composites: A review. Composites Part A: Applied Science and Manufacturing 41: 806-819.

34. La Mantia FP, Morreale M (2011) Green composites: A brief review. Composites Part A: Applied Science and Manufacturing 42: 579-588.

35. Ramirez MGL, Satyanarayana KG, Iwakiri S, de Muniz GB, Tanobe V, et al. (2011) Study of the properties of biocomposites. Part I. Cassava starch-green coir fibers from Brazil. Carbohyd Polym 86: 1712-1722.

36. Luckachan GE, Pillai CKS (2011) Biodegradable Polymers- A Review on Recent Trends and Emerging Perspectives. J Polym Environ 19: 637-676.

37. Adeosun SO, Lawal GI, Balogun Sambo A, Emmanuel Al (2012) Review of Green Polymer Nanocomposites. J Min Mater Character Eng 11: 483-514.

38. Marina MNK (2013) Evaluation of potential of Castor bean cake in the preparation of Micro composites and 'Green' Nano Composites (Avaliação do Potencial do uso da Torta de Mamona Ricinus Communis) para Composito Plasticizada com Glicerol e Nanocompósitos Reforçados com Nanofibrilas de Celulose), Federal University of Parana (UFPR), Curitiba, Paraná. Ph.D. Thesis in Engineering and Materials Scicence. (In Portuguese).

39. Marina MNK, Washington LEM, Satyanarayana KG, Elaine CL (2013) Evaluation of physical and mechanical properties of nanocomposites of casto oil cake based starch reinforced with nanocellulose. Proc. VII Workshop on Applied Nanotechnology to Agrobusiness. 10-13 June, 2013, pp.241-243. Embrapa Instrumentação, São Carlos, Brazil.

40. Tang C (2013) Next-generation renewable polymers. Green Materials 1: 62-63.

41. Dastidar TG, Netravali A (2013) Cross-Linked Waxy Maize Starch-Based "Green" Composites. ACS Sustainable Chem Eng 1: 1537-1544.
42. Lomelí-Ramírez MG, Kestur SG2, Manríquez-González R3, Iwakiri S4, de Muniz GB5, et al. (2014) Bio-composites of cassava starch-green coconut fiber: part II-Structure and properties. Carbohydr Polym 102: 576-583.

43. Baishya P, Maji TK (2014) Studies on Effects of Different Cross-Linkers on the Properties of Starch-Based Wood Composites. ACS Sustainable Chem Eng 2: $1760-1768$.

44. Thakur VK, Thakur MK, Raghavan P, Kessler MR (2014) Progress in Green Polymer Composites from Lignin for Multifunctional Applications: A Review. ACS Sustainable Chem Eng 2: 1072-1092.

45. Thakur VK, Thakur MK2 (2014) Processing and characterization of natural cellulose fibers/thermoset polymer composites. Carbohydr Polym 109: 102 117.

46. Thakur VK, Thakur MK, Gupta RK (2014) Review: Raw Natural Fiber-Based Polymer Composites. Inter J Polym Ana Charact 19: 256-271.

47. Cao Y, Shibata S, Fukumoto I (2006) Mechanical properties of biodegradable composites reinforced with bagasse fiber before and after alkali treatments. Composites Part A: Applied Science and Manufacturing 37: 423-427.

48. Huang M, Yu J, Ma X (2005) Ethanolamine as a novel plasticizer for thermoplastic starch. Polym Degrad Stab 90: 501-507.

49. Tserki V, Matzinos P, Panayiotou C (2006) Novel biodegradable composites based treated lignocellulosic waste flour as filler. Part II: Developmen biodegradable composites using treated and compatibilized waste flour. Composites Part A: Applied Science and Manufacturing 37: 1231-1238.

50. Luo S, Netravali AN (1999) Interfacial and mechanical properties of environmental friendly "green" composites made from pineapple fibers and poly (hydroxybutyrate-covalerate) resin. J Mater Sci 34: 3709-3719.

51. Misra S, Tripathy S, Misra M, Mohanty AK, Nayak SK (2002) Novel EcoFriendly Biocomposites: Biofiber Reinforced Biodegradable Polyester Amide Composites-Fabrication and Properties Evaluation. J Reinf Plastics \& Compos 21: 55-70.

52. Sousa MV, Monteiro SN, d'Almeida, JRM (2004) Evaluation of pre-treatment, size and molding pressure on flexural mechanical behavior of chopped bagasse polyester composites. Polym Testing 23: 253-258.

53. Choi JS, Lim ST, Choi HJ, Mohanty AK, Drzal LT, et al. (2004) Preparation and characterization of plasticized cellulose acetate biocomposite with natural fiber. J Mater Sci 39: 6631-6633. 